\title{
YERBILIMLERI
}

Bulletin for Earth Sciences

Yerbilimleri, 2020, 41 (2), 147-168, DOI:10.17824/yerbilimleri.663521

Hacettepe Üniversitesi Yerbilimleri Uygulama ve Araştırma Merkezi Bülteni

Bulletin of the Earth Sciences Application and Research Centre of Hacettepe University

\section{Rayleigh dalgası Eliptisitesi kullanılarak S- Dalga Hız Yapısının Elde Edilmesi: Erzurum Örneği}

Determining S-wave velocity structure using Rayleigh wave ellipticity: The case study of Erzurum

\section{EREN PAMUK ${ }^{1}$, ÇAĞLAR ÖZER ${ }^{2,3}{ }^{*}$}

${ }^{1}$ Maden Tetkik ve Arama Genel Müdürlüğü, Jeofizik Etütleri Dairesi, 06800, Ankara, Türkiye

${ }^{2}$ Atatürk Üniversitesi, Deprem Araştırma Merkezi, 25240, Erzurum, Türkiye

${ }^{3}$ Atatürk Üniversitesi, Mühendislik Fakültesi, Inşaat Müh. Bölümü, 25240, Erzurum, Türkiye

Geliş (received): 23 Aralık (December) 2019 Kabul (accepted) : 10 Ağustos (August) 2020

Öz

S-dalga hızı (Vs) yerel zemin etkilerinin belirlenmesinde ve zemin dinamik analizi çalışmalarında oldukça önemli bir parametredir. Vs, klasik jeofizik yöntemler ile kolaylıkla elde edilebildiği gibi son yıllarda yapılan çalışmalarda Y/D (Yatay/Düşey) temel mod Rayleigh dalgası eliptisitesinin ters çözümü ile de elde edilmektedir. Bu çalışmada Erzurum'da bulunan, Afet ve Acil Durum Yönetimi ve Atatürk Üniversitesi Deprem Araştırma Merkezi tarafından işletilen üç adet deprem istasyonunda kaydedilen gürültü kayıtları yardımıyla her bir istasyona ait bir boyutlu (1-B) S-dalga hız yapısı ortaya konulmuştur. Öncelikle üç istasyon tarafından kaydedilen üç bileşen (D-B, K-G, Z) mikrotremor kaydının sürekli dalgacık dönüşümü yardımıyla temel mod Rayleigh dalgası eliptisitesi elde edilmiştir. Sonraki aşamada eliptisite eğrisi Komşuluk Algoritması ile ters çözüm yapılarak 1-B'lu Vs derinlik kesitleri oluşturulmuştur. Son olarak elde edilen 1-B'lu Vs derinlik kesitlerinin doğruluğunu ve güvenilirliğinin sınanması amacıyla Vs derinlik kesitleri yardımıyla teorik Y/D spektral oranları elde edilmiş ve Nakamura yöntemiyle elde edilen Y/D spektral oranları ile karşılaştırılmıştır. Vs değerleri üç istasyon için yaklaşık 160 m derinliğe kadar düşük hata değerleri ile hesaplanmıştır.

Anahtar kelimeler: Eliptisite, Rayleigh dalgası, ters çözüm, Y/D spektral oranları, Erzurum.

https://doi.org/10.17824/yerbilimleri.663521

\section{Ç. ÖZER caglarozer@atauni.edu.tr}

\footnotetext{
1 Maden Tetkik ve Arama Genel Müdürlüğü, Jeofizik Etütleri Dairesi, 06800, Ankara, Türkiye ORCID 0000-0002-9511-7951

${ }^{2}$ Atatürk Üniversitesi, Deprem Araştırma Merkezi, 25240, Erzurum, Türkiye ORCID 0000-0001-5401-2013

${ }^{3}$ Atatürk Üniversitesi, Mühendislik Fakültesi, Inşaat Müh. Bölümü, 25240, Erzurum, Türkiye ORCID 0000-0001-5401-2013
} 


\section{ABSTRACT}

S-wave velocity (Vs) is an important parameter in determining local site effects and soil dynamic analysis studies. The Vs can be easily obtained by conventional geophysical methods, but it is also obtained from $\mathrm{H} / \mathrm{V}$ (Horizontal/Vertical) fundamental mode by inversion of Rayleigh wave ellipticity in recent studies. In this study, one dimensional (1-D) S-wave velocity structures of each earthquake station location were determined by microtremor measurements recorded at three stations operated by Disaster and Emergency Management and Atatürk University Earthquake Research Center in Erzurum. Firstly, the fundamental mode Rayleigh wave ellipticity was obtained by the help of continuous wavelet transform of three components (E-W, N-S, Z) microtremor measurement recorded by three stations. In the next step, 1-D Vs structure was obtained with the inversion of the ellipticity curve with the help of the Neighbourhood Algorithm. Finally, in order to test the accuracy and reliability of the obtained 1-D Vs depth-sections, theoretical $H / V$ ratio spectra was obtained with the help of Vs depth-sections compared with $H / V$ ratio spectra achieved by Nakamura method. Vs values were calculated approximately at $160 \mathrm{~m}$ with very low error for three stations.

Keywords: Ellipticity, Rayleigh wave, inversion, $H / V$ spectral ratio, Erzurum.

\section{GíRiş}

Alp-Himalaya dağ kuşağında bulunan genç ve aktif tektonik birimler üzerinde konumlanmış ülkemizde Afet ve Acil Durum Yönetimi Deprem Dairesi Başkanlığı verilerine göre her yıl 20.000'in üzerinde deprem meydana gelmektedir. Doğal bir olay olan depremin engellenmesi mümkün olmayıp, deprem ile mühendislik anlamında mücadele etmek ve zararlarını azaltmak çok önemlidir. Son 20 yıldaki hasar yapıcı 17 Ağustos 1999 İzmit-Gölcük, 12 Kasım 1999 Düzce ve 23 Ekim 2011 Van depremleri sonucu çıkan hasarlar incelendiğinde deprem-zemin-yapı ilişkisi gözetilmeden inşa edilen yapılardaki hasarlar, bu konunun önemine işaret etmektedir. Bu motivasyon ile depreme dayanıklı yapı tasarımında zeminin dinamik davranışlarının anlaşılmasına yönelik yapılan çalışmalar kıymetlidir. Mühendislik saha tasarımında zeminin dinamik davranışının anlaşılması için kayma dalgası (Vs) hız yapısının belirlenmesi önemlidir. Kayma dalgası hızı zeminin elastik özelliklerini ve sismik davranışının belirlenmesinde yaygın olarak kullanılmaktadır. Vs'nin 30 
metre derinliğe kadar olan ortalamasına $\left(\mathrm{Vs}_{30}\right)$ göre zemin özelliklerinin sınıflandırılması NEHRP (National Earthquake Hazard Reduction Programme) (BSSC, 1997), Türkiye Deprem Yönetmeliğine (TDY) (TDY, 2018) ve Eurocode 8 zemin sınıflama kriterlerine göre (CEN, 2004) yapılabilmektedir.

S-dalga hızı (Vs) yerel zemin etkilerinin belirlenmesinde oldukça önemli bir parametre olduğundan sismik mikro bölgeleme çalışmalarında yaygın olarak kullanılmaktadır (Över vd., 2011; Büyüksaraç vd., 2013, 2014; Pamuk vd., 2018, 2019). Nakamura (1989) geliştirdiği ve gürültü kayıtlarından yararlanan Yatay/Düşey (Y/D) spektral oranı yöntemi, genellikle zeminin baskın frekansını belirlemek için kullanılan bir yöntemdir (Mirzaoğlu ve Dikmen 2003, Yalçınkaya ve Alptekin 2005; Pamuk vd., 2018, 2019; Bekler vd., 2019; Akkaya ve Özvan, 2019; Özer, 2019). Ayrıca son yıllarda yapılan çalışmalarda Y/D spektral oran yönteminden elde edilen Rayleigh dalgasının eliptisitesi kullanılarak bir boyutlu (1-B) S-dalga hız yapısı başarılı bir şekilde elde edilmektedir (Fah vd., 2003, 2009; Parolai vd., 2006; Picotti vd., 2017). Shabani vd. (2008) Tahran (İran)'ın güneyinde yer alan bölgede S-dalga hız yapısının elde edilmesi için mikrotremor dizilim yönteminin yanı sıra Rayleigh dalgası elipisitesinin ters çözümünü kullanmışlardır. Burjánek vd. (2011) Rayleigh dalgası eliptisitesini ve Rayleigh dalgası dispersiyon eğrilerini birlikte ters çözüm yaparak çalışma alanı için bir boyutlu (1-B) Vs yapısını elde etmişlerdir. Rosa-Cintas vd. (2017) yapmış oldukları çalışmada Malaga (İspanya) şehrinin farklı alanlarında Sdalga hızlarını belirlemek için Y/D spektral oranlarından elde edilen Rayleigh dalgası eliptisitesini kullanmışlardır. Ullah ve Prado, 2017 yılında yapmış oldukları çalışmada çok kanallı yüzey dalgası analizi (ÇKYD) yöntemiyle elde ettikleri Rayleigh dalgası dispersiyon eğrileri ile Rayleigh dalgası eliptisitesini birlikte ters çözüm yaparak Brezilya'nın Sao Paulo şehrinde yer alan bir krater alanında yumuşak zemin kalınlığını tespit etmişlerdir. Layadi vd., (2018) S-dalgası hız yapısını Rayleigh dalgası eliptisitesinin ters çözümü yöntemi ile elde etmişlerdir. Marcucci vd. (2019) İtalya'nın Roma şehrinde derin anakaya yapısı için Rayleigh dalgası eliptisitesi, Rayleigh dalgası dispersiyon eğrisi ve baskın frekans değerlerini birlikte ters çözüm yapmışlardır. Ashayeri vd. (2019) İran'ın Sarpol-e-zahab bölgesinde gerçekleştirdikleri çalışmada S-dalga hız yapısını elde etmek için Rayleigh dalgası eliptisitesi ile Y/D spektral oran piklerini birlikte kullanmışlardır. Anggono vd. (2019) Endonezya'nın Tangerang bölgesinde yer alan bir deprem istasyonu zemininin Sdalga hız yapısını belirlemek için Rayleigh dalgası eliptisitesi ters çözümünü kullanmışlardır. Issaadi vd. (2020) Cezayir'in kuzeyinde yer alan Oued-Fodda 
şehrinde yapmış oldukları çalışmayla Rayleigh dalgası eliptisitesi ters çözümü ile zeminin 1-B'lu Vs yapısını elde etmişlerdir. Darko vd. 2020 yılında Kanada'da yer alan Windsor (Ontario) bölgesinde yapmış oldukları çalışmada S-dalga hız yapısını elde etmek için Rayleigh dalgası eliptisitesi ile Rayleigh dalgası dispersiyon eğrilerini birlikte ters çözüm yapmışlardır. Rezaei vd. (2020) bir heyelan bölgesi için yapmış oldukları çalışmada öncelikle RayDec yöntemiyle Rayleigh dalgası eliptisitesini elde etmişlerdir. Daha sonra Rayleigh dalgası eliptisitesinin ters çözümü ile elde ettikleri 1B'lu Vs değerlerini kullanarak çalışma alanı için 3-B'lu Vs yapısını belirlemişlerdir.

Bu çalışmada Afet ve Acil Durum Yönetimi (AFAD) ve Atatürk Üniversitesi Deprem Araştırma Merkezi (ATA-DAM) tarafından işletilen Erzurum ve yakın çevresinde konumlanan üç adet deprem istasyonunda kaydedilen gürültü kayıtları yardımıyla her bir istasyona ait 1-B' lu S-dalga hız yapıları ortaya konulmuştur. Çalışmanın ilk aşamasında bir saatlik gürültü verilerinin dalgacık dönüşümü yardımıyla Rayleigh dalgası eliptisitesi elde edilmiştir. Daha sonra Rayleigh dalgası eliptisite eğrileri Komşuluk Algoritması ile ters çözüm yapılarak çalışmada kullanılan istasyonlara ait S-dalga hız yapısı elde edilmiştir. Bilindiği gibi S-dalga hız yapısının elde edilmesi için çok sayıda sismik yöntem mevcuttur (Örneğin sismik kırılma, yüzey dalgalarının çok kanallı analizi (MASW), dizilim mikrotremor (SPAC), kırılma-mikrotremor (ReMi)). Gerek ekonomik nedenler gerek zaman açısından mikro bölgeleme çalışmalarında sıklıkla kullanılan S-dalga hız yapısının elde edilmesi bazı durumlarda mümkün olmamaktadır. Özellikle en az 60 dakikalık bir gürültü verisi kullanılarak S-dalga hız yapısı hakkında ön bilgi sahibi olmak büyük avantaj sağlamaktadır. Bu perspektif ile Erzurum'da AFAD ve ATA-DAM tarafından işletilen üç adet istasyondaki gürültü verileri kullanarak ilgili istasyonların altındaki 1-B'lu Vs yapısı ortaya konmuştur.

\section{RAYLEIGH DALGASI ELIPTISITESI VE TERS ÇÖZÜMÜ}

Tanecik hareketi elips şeklinde ve hareketi yayılma doğrultusuna ters yönde (retrograd) olan Rayleigh dalgaları yarı sonsuz homojen olan bir elastik ortamda yayılmaktadır (Aki, 1965). Rayleigh dalgaları, P (birincil dalgalar) ve SV (S-dalgasının düşey bileşeni) dalgalarının doğrusal girişimleriyle oluşmaktadır (Aki, 1965). Ayrıca, Rayleigh dalgalarının dispersiyon göstermesi için tabakalı bir ortamda yayılması gerekmektedir. Düşey ve yatay bileşenlerin girişiminde faz kayması $\pm \pi / 2$ 'dir. Faz 
kaymasının artı veya eksi olmasına bağlı olarak tanecik hareketi retrograde (ters) veya prograde (ileri) yönde ilerler. Homojen yarı sonsuz ortamda parçacık hareketi tüm frekanslarda geriye doğru gider ve eliptisite sabittir. Ancak tabakalı bir ortam durumunda eliptisite sabit olmayıp, partikül hareketi anakaya ile zemin arasındaki kontrasta bağlı olarak retrograde eliptik hareketten prograde eliptik harekete geçiş yapmaktadır (Konno ve Ohmachi, 1998; Ullah, 2017). Y/D spektral oranları temel mod Rayleigh dalgasının eliptisitesini yansıtmakta olup birçok araştırmacı tarafından kullanılmaktadır (Nogoshi ve Igarashi 1971, Yamanaka vd., 1994; Fäh vd., 2001, Fäh vd., 2003, Ullah, 2017).

Serbest yüzeydeki yer hareketinin eliptisitesi, her frekanstaki yatay ve düşey yer değiştirme öz fonksiyonları (eigen-functions) arasındaki oran olarak tanımlanır (Fäh vd., 2009). Eliptisite, temel baskın frekansındaki pik ile yüksek frekanstaki ilk minimum arasındaki Y/D spektral oranı ile tespit edilebilmektedir (Fah vd., 2001). Dolayısıyla Y/D spektral oranının şekli kullanılarak yerin 1-B'lu S- dalga hız yapısı ortaya çıkartılabilmektedir. Bu yöntem kullanılarak anakayanın hem sığ hem de derin olduğu alanlarda başarılı sonuçlar elde edilmiştir (Fäh vd., 2001; Parolai vd., 2006).

Zeminin 1-B'lu sismik hız yapısı Rayleigh dalgalarının yer içerisindeki yayılımını dolayısıyla zemin üzerinden mikrotremor ölçüleri yardımıyla elde edilen Y/D spektral oranların şeklini etkilemektedir (Picotti vd., 2017). Dolayısıyla temel moddaki Rayleigh dalgalarının eliptisitenin ters çözümü ile zeminin 1-B 'li hız yapısı elde edilebilir (Fäh vd., 2001; Picotti vd., 2017). Bu ters çözüm işlemi sürekli dalgacık dönüşümü yardımıyla gerçekleştirilebilir (Fäh vd., 2001).

Y/D spektral oranlarından eliptisiteyi elde etmek için öncelikli olarak cisim dalgalarının ve Love dalgasının enerjilerinin belirlenmesi gerekmektedir. Bunun için Fäh vd. (2001) önerdiği yöntem ile sinyal boyunca P-SV dalgaları tanımlanır ve sadece bu dalgacıklardan gelen spektral oran hesaplanarak $\mathrm{SH}$ etkisi azaltılmış olur. $\mathrm{Bu}$ yöntem üç bileşenin (K-G, D-B ve Z) her birinin zaman-frekans analizi ile yapılabilir. Düşey bileşenin zaman-frekans analizinde, enerjisi yüksek olan alanlar her bir frekans için zaman içinde tanımlanmaktadır. Bu maksimum, Y/D oranının hesaplandığı tek bir Rayleigh dalgacığı ile ilgili olduğu varsayılmaktadır. Tüm dalgacıkların üzerindeki ortalama, Y/D spektral oranını betimlemektedir. Böylece temel mod Rayleigh dalgalarının eliptisitesi, bu eğri yardımıyla elde edilebilir (Fah vd., 2009). NERIES projesi (Fäh vd., 2009) kapsamında doğrudan Rayleigh dalgalarının tespiti, zaman frekans analizleri ile düzenlenmiş Morlet dalgacıkları ve 
Sürekli Dalgacık Dönüşümü (CWT) kullanılarak geliştirilmiştir. NERIES projesi kapsamında eliptisite eğrileri, pik frekans değerleri ile dispersiyon eğrileri birlikte ters çözüm yapılmış ve başarılı sonuçlar elde edilmiştir.

\section{Sürekli Dalgacık Dönüşümü (SDD) ile Y/D Spektral Oranların Hesaplanması}

Sürekli Dalgacık Dönüşümü (SDD) ile Y/D spektral oranların hesaplanması Fäh vd. (2009)'nin çalışmasından özetlenmiştir. Zaman frekans yönteminin temelini oluşturan sürekli dalgacık dönüşümünü kısaca açıklamak gerekirse; zaman ortamında bir $\mathrm{x}(\mathrm{t})$ fonksiyonun sürekli dalgacık dönüşümü Eşitlik 1'de verilmiştir;

$\operatorname{SDD}\{\mathrm{x}(\mathrm{t})\}_{\mathrm{a}, \mathrm{b}}=\frac{1}{\sqrt{|\mathrm{a}|}} \int_{-\infty}^{\infty} \mathrm{x}(\mathrm{t}) \Psi^{*}\left(\frac{\mathrm{t}-\mathrm{b}}{\mathrm{a}}\right) \mathrm{dt}$

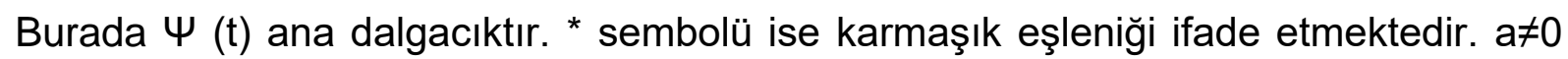
ve b gerçek olmak üzere, a ölçeklendirme ve b öteleme parametreleridir. Küçük ölçeklendirme parametresi (a) sinyali sıkıştırır ve yüksek frekanslarda kullanılır. Ölçeklendirme parametresi (a) büyük olduğunda sinyali genişletir ve düşük frekanslarda kullanılır (Türkkan, 2015).

Zaman-frekans yönteminde klasik Nakamura yöntemi gibi mikrotremorlerin düşey ve yatay bileşenlerinin genlik spektrumları oranından yararlanılmaz. Bu yöntemde tüm bileşenlerin (D-B, K-G ve Z) zaman-frekans gösterimleri SDD yardımıyla hesaplanır. Her iki yatay bileşenin dalgacık dönüşümü eşitlik 2 ile birleştirilir (Fäh vd., 2009).

$$
\left|\mathrm{SDD}_{\mathrm{Y}}\right|=\sqrt{\mathrm{SDD}_{\mathrm{DB}}^{2}+\mathrm{SDD}_{\mathrm{KG}}^{2}}
$$

Burada $S D D_{D B}$ ve $S D D_{K G}$ bu ifadeler sırasıyla D-B ve K-G bileşenlerin dalgacık dönüşümlerini ifade etmektedir. Bilindiği gibi, Love dalgalarının aksine Rayleigh dalgaları düşey bileşen üzerinde maksimum enerjiye sahiptir. Bu nedenle, çoğunlukla Rayleigh dalgalarını tespit edebilmek için, SDD' nin mutlak değeri düşey bileşen $\left(\left|\mathrm{SDD}_{\mathrm{Z}}\right|\right)$ için tüm maksimum değerlerde taranmaktadır (Fäh vd., 2009). Zaman ekseninde tanımlanan her bir maksimum için $\mathrm{SDD}_{H}$ değeri bir çeyrek periyot gecikme ile piklenir. Bu Rayleigh dalgasının düşey ve yatay bileşenleri arasındaki teorik gecikmedir. Bu gecikme pozitif (Prograde parçacık hareketi) veya negatif (retrograde parçacık hareketi) olabilmektedir. Yatay ve düşey değerler arasındaki oran düşey bileşen üzerinde bulunan her bir maksimum için kaydedilir. Bu işlem her bir frekans 
$\left(f_{i}\right)$ için tekrarlanır (Fäh vd., 2009). Her frekans için kaydedilen oranlar istatistiksel olarak analiz edilmektedir. Bir logaritmik skala ile her frekans için bir histogram oluşturulur. Ayrılmış Rayleigh dalgaları modları için ideal bir durumda, 2-B histogramı, tepe noktası eliptisiteye tekabül eden, iyi tanımlanmış bir sırt sergilemelidir (Fäh vd., 2009).

\section{Komşuluk Algoritması (KA) ile Ters Çözüm}

$\mathrm{Bu}$ çalışmada, rassal bir yöntem olan Komşuluk Algoritması (KA) Rayleigh dalgalarının eliptisitesinin ters çözümünde kullanılmıştır (Sambridge, 1999; Wathelet vd., 2005). Sambridge (1999) geliştirdiği KA, Voronoi hücrelerine dayanan doğrudan bir arama algoritmasıdır. Bu algoritma modelleri iyileştirmek için önceki modeller kullanılır. Yerel minimumlardan kaçma kabiliyetine sahip olan bu algoritma parametre uzayının en uygun kısmını araştırmak ve bulmak için Voronoi hücrelerinin geometrisinden yararlanır (Sambridge, 1999; Wathelet, 2005; Pamuk vd., 2015). Önceden tanımlanmış parametre uzayında çok sayıda rasgele model üretilmesinden dolayı ters çözüm için tek bir çözüm yoktur. Parametre uzay için gerekli parametreler S-dalgası hızı (Vs), P-dalgası hızı (Vp), yoğunluk, Poisson oranı ve tabaka kalınlıklarıdır. Üretilen her bir model için temel moddaki Rayleigh dalgasının eliptisitesi düz çözüm ile hesaplanmaktadır. Ölçülen ve hesaplanan eliptisite arasındaki hata fonksiyonu eşitlik 3 yardımıyla hesaplanır (Wathelet, 2005).

Hata Değeri $=\sqrt{\frac{1}{N} \sum_{i=1}^{N}\left(\frac{E_{\text {mod }}-E_{\text {trs }}}{\sigma_{i}}\right)^{2}}$

Burada $E_{\text {trs }}$ ters çözümü gerçekleştirilen eliptisite eğrisini, $E_{\bmod }$ teorik olarak elde edilen Eliptisite eğrisini temsil etmektedir. $\sigma$ ise i frekansındaki verilerin standart sapmasıdır.

\section{VERI TOPLAMA VE ANALIZi}

Bu çalışmada Afet ve Acil Durum Yönetimi (AFAD) ve Atatürk Üniversitesi Deprem Araştırma Merkezi (ATA-DAM) tarafından işletilen (Özer vd., 2019) üç adet istasyona ait altmış dakikalık gürültü verileri kullanılmıştır (Şekil 1). Çalışmada EDAM istasyonun lokasyonunda ivme-ölçer kurulu olduğundan bu lokasyonda ayrıca bir saat hız-ölçer sensör ile mikrotremor ölçümü yapılmıştır. Bu noktada yapılan 
çalışmalar bundan sonra EDAM olarak adlandırılacaktır. Gürültü seviyesinin düşük olması sebebiyle saat 03:00-04:00 arasında kaydedilen hava koşullarının uygun olduğu (kar/yağmur yağışının olmadığı) veri seti seçilerek kullanılmıştır. Çalışma için öncelikli olarak klasik Nakamura yöntemi kullanılarak sismometrenin üzerinde bulunduğu zemininin fiziksel özelliklerini yansıtan parametreler (zemin hâkim titreşim periyodu (t) ve Büyütme Faktörü $(A)$ ) belirlenmiştir. Bunun için 60 dakikalık mikrotremor verisinin trend etkisi giderildikten sonra üç bileşene (D-B, K-G, Z) 0.5-20 $\mathrm{Hz}$ aralığında bant geçişli süzgeç uygulanmıştır. Pencere boyu 50 sn olarak belirlenmiş ve Hızlı Fourier Dönüşümü (FFT) uygulanarak her bir bileşene ait genlik spektrumları elde edilmiştir. Elde edilen spektrumlara ise band genişliği $b=40$ seçilerek Konno-Ohmachi yuvarlatması uygulanmıştır. Sonuç olarak Yatay bileşenlerin genlik spektrumunun düşey bileşen genlik spektrumlarına oranlanması ile Y/D oran spektrumları üç istasyon için elde edilmiştir (Şekil 2).

Bu çalışmada Rayleigh dalgası eliptisitesi elde edilirken öncelikle üç bileşenin (D-B, $K-G, Z)$ Fourier dönüşümleri hesaplanmıştır. $f_{c}$ frekansı etrafında ortalanan frekans ortamındaki düzenlenmiş Morlet dalgacığı eşitlik 4'de sunulmaktadır (Fah vd., 2009);

$\Psi(w)=\frac{1}{\sqrt[4]{\pi}} \exp \left(-\left(\frac{\mathrm{f}}{\mathrm{f}_{\mathrm{c}}} \mathrm{w}_{0}-\mathrm{w}_{0}\right)^{2} \mathrm{~m}\right)$

Burada f frekans, $w_{0}$ birinci Morlet parametresi, m ikinci Morlet parametresidir.

$\mathrm{Bu}$ fonksiyon üç bileşenle konvolüsyon yapılır ve daha sonra zaman ortamına geri dönülerek karmaşık bir sinyal sağlanır. Burada $w_{0}$ parametresi 6 olarak kullanılır ve m değişken parametre olarak belirlenir. Yatay bileşenlerin (YB) karmaşık sinyalleri Eşitlik 5'deki gibi gruplandırılır (Fah vd., 2009):

$$
\mathrm{YB}=\sqrt{\mathrm{DB}^{2}+\mathrm{KG}^{2}}
$$

Karmaşık düşey ve karmaşık yatay bileşenlerin mutlak değerleri hesaplanır. Düşey bileşen üzerindeki tüm maksimumları için zaman ve genlik korunur. Yatay bileşen üzerindeki genlikler düşey piklere göre $+/-90^{\circ}$ ile değişen zamanlarda ölçülmektedir. 


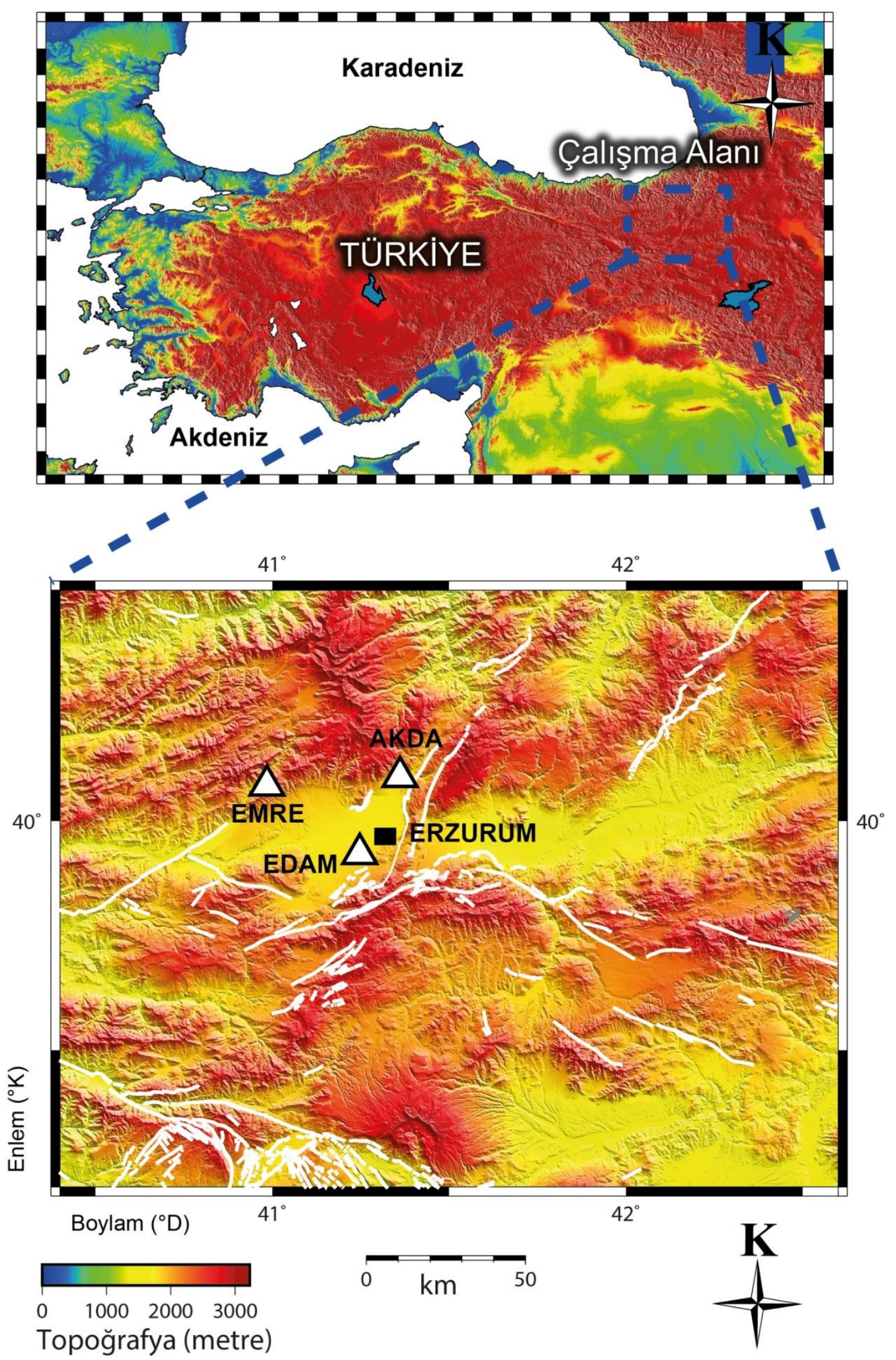

Şekil 1. Çalışmada kullanılan EDAM, AKDA ve EMRE istasyonlarının lokasyonları.

Figure 1. Locations of EDAM, AKDA and EMRE stations used in the study. 


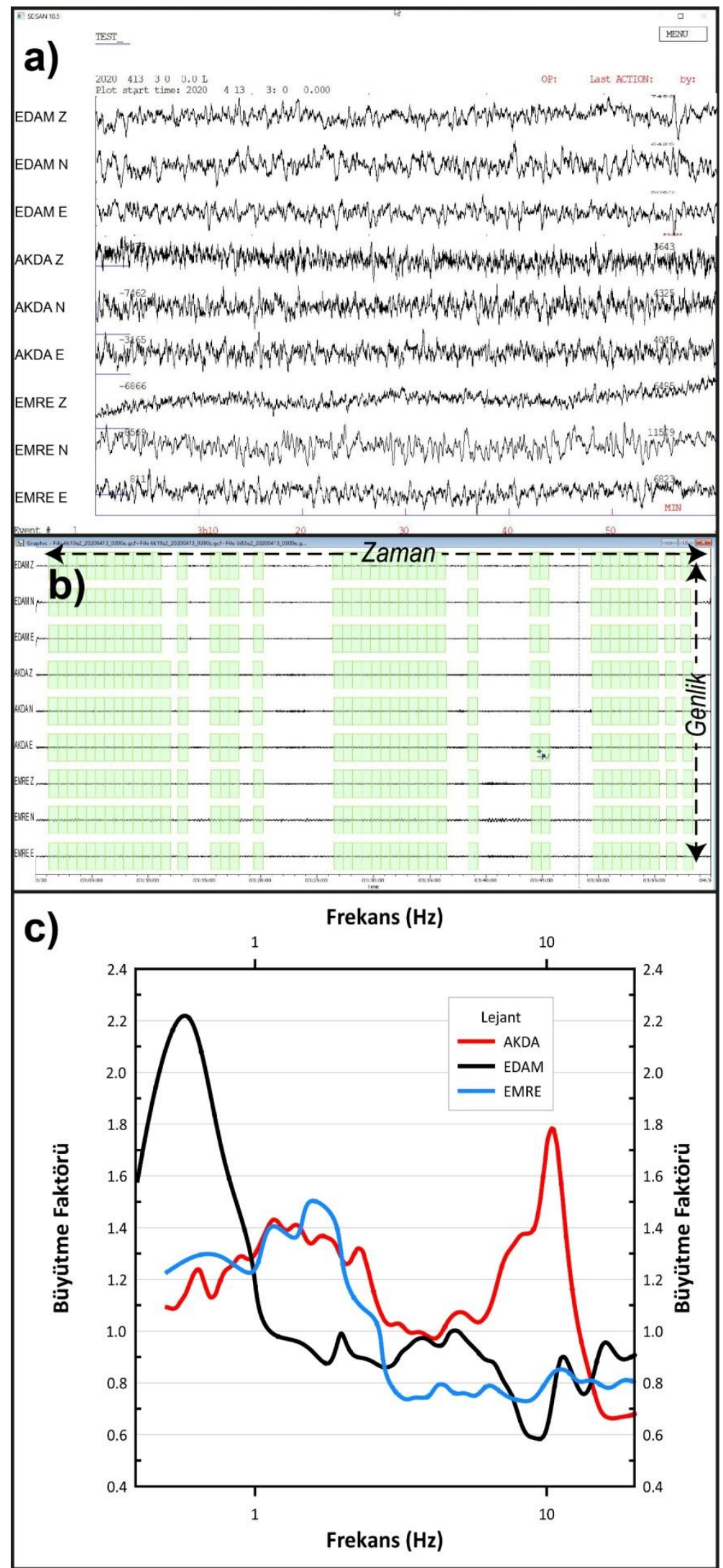

Şekil 2. a) EDAM, AKDA ve EMRE istasyonlarında kaydedilen üç bileşen gürültü (D-B, K-G ve Z) verisi b) Üç bileşen üzerinde pencere seçimi (pencere boyu:50 sn) c) Her bir pencere için hesaplanan yatay genlik spektrumlarının düşey genlik spektrumlarına oranlanması sonucu elde edilen ortalama Y/D oran spektrumu. 
Figure 2. a) Three components (EW, NS and Z) microtremor data recorded at EDAM, AKDA and EMRE stations b) Window selection on three components (window length: $50 \mathrm{sec}$ ) c) Average $H / V$ ratio spectra obtained from ratio of horizontal amplitude spectra to vertical amplitude spectra for each window.

Tüm düşey olarak heterojen zemin yapıları için yatay Rayleigh bileşeni düşey bileşene göre her zaman $90^{\circ}$ geciktirilir. Eliptisite oranı tüm frekanslarda görünür bir sayıdır. Ayrıca bu işlemler seçilen tüm frekanslar için tekrarlanmaktadır. Histogramdan eliptisite eğrisi iki farklı yolla elde edilebilir (Fah vd., 2009). Birinci yol belirlenen frekans için histogram değerlerinin (olası yoğunluk fonksiyonu) geometrik ortalamasıdır. İkinci yol ise manuel işaretlemedir. Belirli frekanstaki olası yoğunluk fonksiyonunun en büyük değerleri o frekanstaki eliptisiteye karşılık gelmektedir (Fah vd., 2009). Bu çalışmada histogram değerlerinin geometrik ortalaması ile eliptisite değerleri elde edilmiştir (Şekil 3a, d, g).

Rayleigh eliptisitesinin ters çözümünde yukarıda açıklanan Komşuluk Algoritması kullanılmıştır. Bu ters çözüm işlemi Geopsy programının alt paketi olan Dinver yazılımı ile gerçekleştirilmiştir (Sesame, 2004). Ters çözüm için gerekli olan parametre uzayının belirlenmesinde Çizelge 1'de verilen parametreler kullanılmıştır. Algoritma üretilen her bir model için Y/D spektrumlarının zaman-frekans analizlerinden elde edilen temel mod Rayleigh dalga eliptisitesi ile teorik olarak oluşturan Rayleigh dalga eliptisitesi arasındaki hata değerini hesaplamaktadır. Her bir model için hesaplanmış en düşük hata değerine sahip model sonuç modeli olarak kabul edilmiştir (Şekil 3).

Bu çalışmanın bir sonraki aşamasında elde edilen Vs derinlik kesitleri kullanılarak teorik Y/D oran spektrumları hesaplanmıştır (Şekil 3c, f, i). Teorik Y/D oran spektrumları hesaplanırken kullanılan diğer parametreler tabakaların P-dalga hızları ve yoğunluklarıdır. Bu çalışmada, Özer ve Özyazıcıoğlu (2019)'nun özellikle AKDA istasyonu olmak üzere diğer istasyonlarda da rapor ettikleri düşük $\mathrm{Vp} / \mathrm{Vs}$ oranlarından hareketle $\mathrm{Vp} / \mathrm{Vs}$ oranı 1.6 seçilerek $\mathrm{Vp}$ değerleri hesaplanmıştır. Tabakaların yoğunluk değerleri sismik hızlar ile yoğunluk arasında ampirik bağıntılar yardımıyla hesaplanmıştır. Destici (2001), Komazawa vd. (2002), Uyanık (2002), Keçeli (2009) ve Uyanık ve Çatlığlu (2015)'nun geliştirmiş oldukları bağıntılar yardımıyla hesaplanan yoğunluk değerlerinin ortalaması alınarak her bir tabaka için tek bir yoğunluk değeri elde edilmiştir. Böylece Rayleigh dalga eliptisitesi yardımıyla 
elde edilen Vs derinlik kesitlerinin doğruluğu ve güvenilirliği test edilmiştir. Teorik Y/D oran spektrumlarının
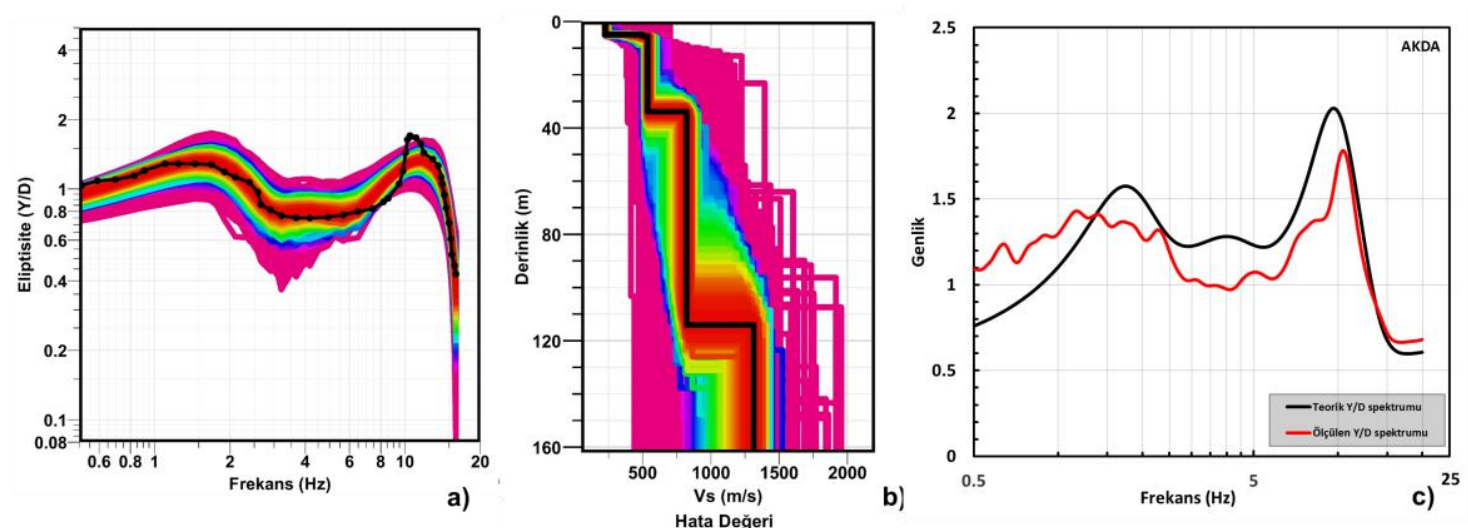

$\begin{array}{lllll}0.12 & 0.14 & 0.16 & 0.18 & 0.20\end{array}$
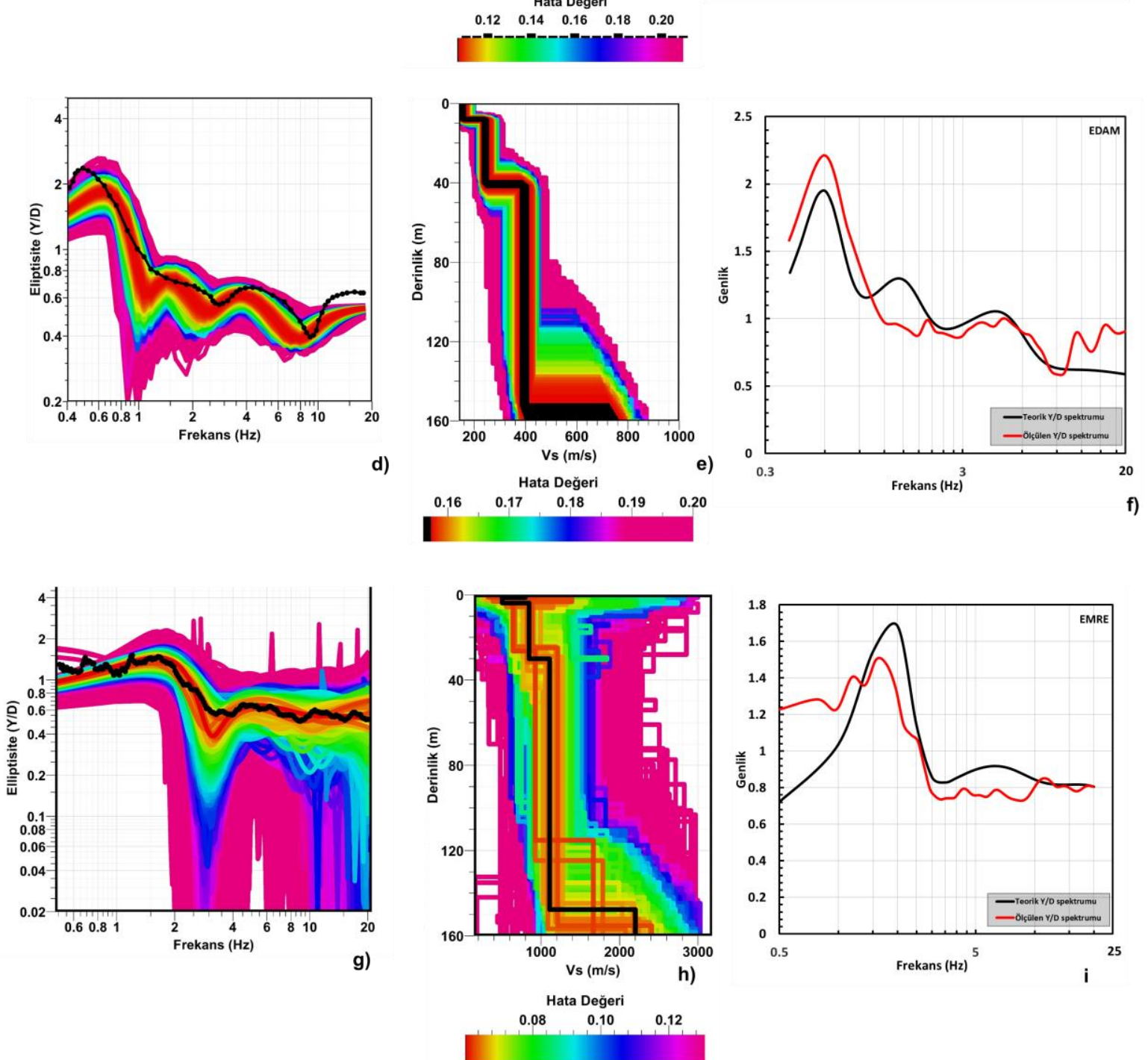

Şekil 3. Rayleigh dalgası eliptisite eğrileri ters çözümü ile AKDA, EDAM ve EMRE istasyon lokasyonlarının S-dalga hız yapısı. a) AKDA istasyonu için ölçülen ve hesaplanan eliptisitefrekans eğrisi (siyah çizgi ölçülen Rayleigh dalgası eliptisite eğrisi, pembeden kırmızıya her bir model için hesaplanan eliptisite eğrisi) b) AKDA istasyonu S- dalga hız yapısı (siyah çizgi en düşük hata oranı ile elde edilen Vs-derinlik kesiti) c) AKDA istasyonu için teorik-ölçülen 
Yatay (Y) / Düşey (D) spektrum eğrisi d) EDAM istasyonu için ölçülen ve hesaplanan eliptisite-frekans eğrisi e) EDAM istasyonu için S-dalga hız yapısı f) EDAM istasyonu için teorik-ölçülen Yatay (Y)/Düşey (D) spektrum eğrisi g) EMRE eliptisite-frekans eğrisi h) EMRE istasyonu için S-dalga hız yapısı i) EMRE istasyonu için teorik-ölçülen Yatay (Y)/Düşey (D) spektrum eğrisi.

Figure 3. S-Wave velocity structure of AKDA, EDAM and EMRE stations with Rayleigh wave ellipsity curvesi inversion. a) Ellipticity-frequency curve measured and calculated for AKDA station (Rayleigh wave ellipticity curve measured from black line, ellipticity curve calculated for each model from pink to red) b) S-wave velocity structure in AKDA station (Black line obtained with lowest error rate) c) Theoretical and measured $H / V$ spectra for AKDA station d) Ellipticity-frequency curve for EDAM station e) S-wave velocity structure for EDAM station f) Theoretical and measured H/V spectra for EDAM station g) Ellipticity-frequency curve for EMRE station $h$ ) S-wave velocity structure for EMRE station i) Theoretical and measured $H / V$ spectra for EMRE station.

hesaplamaları için Herrmann ve Ammon (2002)'ın yazılımından değiştirilerek geliştirilen SurWave yazılımı kullanılmıştır.

\section{JEOLOJi}

Yüzölçümünün \%64'nü dağlar oluşturan Erzurum ili, deniz seviyesine göre ortalama yüksekliği 1900 metre olan ve dağlık kesimlerin yüksekliği 3000 metreye kadar ulaşan, arazi büyüklüğü bakımından Türkiye'nin 4. büyük ilidir (Demirtaş vd., 2010). Demirtaş vd. (2010) Erzurum ve yakın çevresinin, alttan üste doğru gnays, amfibolit, şist ve mermer ardalanmasından oluştuğunu ve genellikle diyabaz, gabro ve yer yer serpantinit ile peridotitten oluşan ofiyolitli karmaşık yaygısının altından tektonik bir pencere biçiminde yüzeylendiğini rapor etmiştir.

EDAM istasyonu Erzurum şehir merkezinde iken AKDA istasyonu şehrin kuzeydoğusunda, EMRE istasyonu ise şehrin kuzeybatısında yer almaktadır. Deprem istasyonlarının kurulu olduğu alana ait jeolojik bilgiler incelendiğinde AKDA istasyonunun yamaç molozu ve moren üzerinde, EDAM istasyonu güncel alüvyonlar üzerinde ve EMRE istasyonu ise karasal kırıntılılar üzerine kurulmuştur (Akbaş vd., 2013). Yapılan arazi gözlemlerinden hareketle en gevşek birim üzerinde kurulu istasyon EDAM'dır. AKDA istasyonu eğimi yüksek sarp bir alanda kurulu olup, EMRE istasyonu nispeten tüm istasyonlara göre kompakt bir alanda kuruludur. Demirtaş vd.(2010)'nin Erzurum ve çevresinde yürüttükleri 1/5000 ölçekli Nazım İmar Planına Esas Jeolojik-Jeoteknik Etüt Raporu sonuçları irdelendiğinde Erzurum havzasının 
orta kesiminde, kalın alüvyal çökel istifin olduğu ve havza kenarlarına doğru gevşek birimlerin azaldığı belirtilmiştir.

Çizelge 1. KA ile yapılan ters çözümde kullanılan en geniş parametre aralığı.

Table 1. Widest parameter range used in KA inversion.

\begin{tabular}{|c|c|c|c|c|c|}
\hline Tabaka & $\mathbf{V p}(\mathbf{m} / \mathbf{s})$ & Vs (m/s) & $\begin{array}{c}\text { Tabaka } \\
\text { kalınlığı }(\mathbf{m})\end{array}$ & $\begin{array}{c}\text { Poisson } \\
\text { Oranı }\end{array}$ & $\begin{array}{c}\text { Yoğunluk } \\
\left(\mathbf{g r} / \mathbf{c m}^{\mathbf{3}}\right)\end{array}$ \\
\hline Tabaka-1 & $200-5000$ & $150-3500$ & $1-160$ & $0.2-0.5$ & 2.0 \\
\hline Tabaka-2 & $200-5000$ & $150-3500$ & $1-160$ & $0.2-0.5$ & 2.0 \\
\hline Tabaka-3 & $200-5000$ & $150-3500$ & $1-160$ & $0.2-0.5$ & 2.0 \\
\hline Tabaka-4 & $200-5000$ & $150-3500$ & $1-160$ & $0.2-0.5$ & 2.0 \\
\hline $\begin{array}{c}\text { Yarı } \\
\text { sonsuz }\end{array}$ & $200-5000$ & $150-3500$ & & $0.2-0.5$ & 2.0 \\
\hline
\end{tabular}

\section{BULGULAR}

Atatürk Üniversitesi Deprem Araştırma Merkezi ve Afet ve Acil Durum Yönetimi tarafından işletilen üç adet istasyonun 1-B'lu sismik hız yapısı, Yatay/Düşey oran spektrumlarından elde edilen temel mod Rayleigh eliptisite eğrileri ters çözümü yardımıyla modellenmiştir.

$\mathrm{Bu}$ perspektifte, hafif eğimde yamaç molozları üzerinde kurulu AKDA istasyonunda yapılan analizlerde çok düşük hata değerlerinde (<0.1) S- dalga yapısı $\sim 160$ metreye kadar dört tabakalı olarak elde edilmiştir. Vs değerleri $235 \mathrm{~m} / \mathrm{s}$ 'den $1300 \mathrm{~m} / \mathrm{s}$ arasında değiştiği tespit edilmiştir. 0-5 m arasında Vs değeri $235 \mathrm{~m} / \mathrm{s}$ olan bir tabaka bulunmaktadır. Bu tabakanın hemen altında yaklaşık $36 \mathrm{~m}$ 'ye kadar uzanan ve Vs değeri yaklaşık $550 \mathrm{~m} / \mathrm{s}$ olan bir tabaka görülmektedir. Bu tabakanın altında derinliği 115 m'ye kadar devam eden yaklaşık Vs değeri $825 \mathrm{~m} / \mathrm{s}$ olan bir tabaka bulunmaktadır. En derinde, S-dalga hızı 1300 m/s olan bir tabaka elde edilmiştir. Bu istasyon için hesaplanan teorik Y/D spektral oranı ile ölçülen Y/D spektral oranın uyumlu olduğu görülmektedir. Her iki spektrumda da $1.75 \mathrm{~Hz}$ ve $9.75 \mathrm{~Hz}$ civarlarında pikler elde edilmiştir ve bu piklere karşılık gelen büyütme faktörü değerleri birbirine yakın değerdedir (Şekil 3a, b, c). AKDA istasyonu için zemin hâkim titreşim periyodu değeri 0.10 sn, büyütme faktörü $(A)$ ise 1.87 olarak hesaplanmıştır (Çizelge 2). 
Alüvyon üzerinde konumlanmış EDAM istasyonunda yapılan gözlemlerde, düşük hata değerlerinde $(<0.17)$ 160 metreye kadar dört tabakalı ortamın kesme dalga hızlarının 140 m/s'den 730 m/s'ye kadar değiştiği gözlenmektedir. Bu istasyondaki teorik ve

Çizelge 2. İstasyonlar için elde edilen sonuçlar ( $\mathrm{t}, \mathrm{A}, \mathrm{Vs}_{10}, \mathrm{Vs}_{30}, \mathrm{Vs}_{50}, \mathrm{Vs}_{100}$ ) ve istasyonların üzerinde bulundukları jeolojik birimler.

Table 2. The results ( $\left.t, A, V s_{10}, V s_{30}, V s_{50}, V s_{100}\right)$ obtained for the stations and the geological units of the stations.

\begin{tabular}{|c|c|c|c|c|c|c|c|}
\hline \multirow{2}{*}{ İstasyon } & \multirow{2}{*}{ Zemin Yapısı } & \multirow{2}{*}{$\begin{array}{c}\text { Baskın } \\
\text { Periyot } \\
(\mathrm{t}(\mathrm{s}))\end{array}$} & \multirow{2}{*}{$\begin{array}{l}\text { Büyütme } \\
\text { Faktörü } \\
\text { (A) }\end{array}$} & \multicolumn{4}{|c|}{ Farklı Derinlikler için Vs (m/s) } \\
\hline & & & & $10 \mathrm{~m}$ & $30 \mathrm{~m}$ & $50 \mathrm{~m}$ & $100 \mathrm{~m}$ \\
\hline AKDA & $\begin{array}{c}\text { Alüvyon } \\
\text { Yelpazesi, } \\
\text { yamaç molozu, } \\
\text { moren }\end{array}$ & 0.10 & 1.87 & 550 & 550 & 825 & 825 \\
\hline EDAM & Alüvyon & 1.68 & 2.21 & 236 & 236 & 410 & 410 \\
\hline EMRE & $\begin{array}{l}\text { Karasal } \\
\text { kırıntılılar }\end{array}$ & 0.57 & 1.57 & 840 & 1050 & 1050 & 1050 \\
\hline
\end{tabular}

hesaplanan Y/D spektral oranlarının $0.6 \mathrm{~Hz}$ ile $20 \mathrm{~Hz}$ arasındaki uyumu tatmin edicidir. 0-8 m arasında Vs değeri $140 \mathrm{~m} / \mathrm{s}$ olan bir tabaka bulunmaktadır. Bu tabakanın hemen altında yaklaşık $41 \mathrm{~m}$ 'ye kadar uzanan ve Vs değeri yaklaşık 236 m/s olan bir tabaka konumlanmaktadır. Bu tabakanın altında derinliği 155 m’ye kadar devam eden tabakanın Vs değeri $\sim 410 \mathrm{~m} / \mathrm{s}$ 'dir. Son tabakada ise, Vs değeri yaklaşık $730 \mathrm{~m} / \mathrm{s}^{\prime}$ dir (Şekil 3d, e, f). EDAM istasyonu için zemin hâkim titreşim periyodu değeri $1.68 \mathrm{~s}$, büyütme faktörü (A) ise 2.21 olarak hesaplanmıştır (Çizelge 2). Demirtaş vd., (2010) 1/5000 ölçekli 160 adet paftayı kapsayan ve EDAM istasyonunun olduğu alandaki araştırmalarında sondaj, MASW, mikrotremor, sismik kırılma ve düşey elektrik sondaj (DES) gibi birçok çalışma yürütmüşlerdir. Bu raporda EDAM istasyonu yakın çevresindeki sondajlar 10-12 metre derinliğe kadardır. Sondajlar dışında bu raporda mikrotremor, DES, MASW çalışmaları yürütülmüştür. V $s_{30}$ dağılım haritası, Erzurum havzasının orta kesiminde, kalın alüvyal çökel istifin olduğu kesimlerde düşük iken, hız değerlerinin havza kenarlarına doğru arttığı belirtilmiştir. Çalışma sahasında yürütülen mikrotremor çalışmasında EDAM istasyonunun olduğu alanda zemin büyütmesi 2 civarında rapor edilmiştir. 
Karasal kırıntılılar üzerinde kurulu EMRE istasyonunda 160 metreye kadar elde edilen beş tabakalı modelde, tatmin edici hata değerlerinde (<0.1) S- dalga hızlarının $500 \mathrm{~m} / \mathrm{s}$ 'den $2200 \mathrm{~m} / \mathrm{s}$ 'ye kadar değişmektedir. Teorik ve hesaplanan Y/D spektral oranlarının $0.5 \mathrm{~Hz}$ ile $20 \mathrm{~Hz}$ arasında uyum içinde eğrilerin çakıştığı gözlenmektedir. 0-1 m arasında Vs değeri $800 \mathrm{~m} / \mathrm{s}$ olan bir tabaka konumlanmaktadır.1-5 m arasında ise Vs değeri $500 \mathrm{~m} / \mathrm{s}$ olan bir tabaka konumlanmaktadır. Bu tabakanın hemen altında yaklaşık 30 m 'ye kadar uzanan ve Vs değeri yaklaşık 840 m/s olan bir tabaka görülmektedir. 30-145 m arasında, yaklaşık Vs değeri $1050 \mathrm{~m} / \mathrm{s}$ olan bir tabaka konumlanmaktadır. En alt tabakada ise S-dalga hızı $2200 \mathrm{~m} / \mathrm{s}$ olan bir tabaka elde edilmiştir (Şekil 3g, h, i). EMRE istasyonu için zemin hâkim titreşim periyodu değeri $0.57 \mathrm{~s}$, büyütme faktörü $(\mathrm{A})$ ise 1.57 olarak bulunmuştur (Çizelge 2).

\section{SONUÇLAR VE ÖNERILER}

ATA-DAM ve AFAD tarafından işletilen üç adet istasyona ait zemin özellikleri istasyonların gürültü verilerinden hareketle Y/D oran spektrumlarından elde edilen temel mod Rayleigh dalgası eliptisite eğrileri ters çözümü yardımıyla kesme dalga hızları hesaplanmıştır. 1-B'lu Vs yapısı çok düşük hata payları ile $160 \mathrm{~m}$ derinliğe kadar tespit edilmiştir. Böylelikle aktif kaynaklı sismik kırılma, MASW yöntemlerine nazaran daha derin Vs-derinlik kesitleri bu yöntemle ortaya konmuştur.

AKDA istasyonunda $36 \mathrm{~m}$ derinliğe kadar Vs değeri $550 \mathrm{~m} / \mathrm{s}$ 'nin altındadır. $36 \mathrm{~m}$ derinlikte $825 \mathrm{~m} / \mathrm{s}$ değerinde hıza ulaşılmıştır. Dolayısıyla yaklaşık $36 \mathrm{~m}$ derinlikte mühendislik anakayası (Vs> $760 \mathrm{~m} / \mathrm{s}$ ) olarak tanımlanabilecek tabakaya ulaşılmıştır. EDAM istasyonunda yaklaşık 160 m derinliğe kadar mühendislik anakayası (Vs> 760 $\mathrm{m} / \mathrm{s}$ ) elde edilememiştir. EMRE istasyonunda ise yaklaşık $30 \mathrm{~m}$ derinlikte mühendislik anakayası tespit edilmiştir.

AKDA, EMRE ve EDAM istasyonu için elde edilen Vs- derinlik kesitleri incelendiğinde belirgin sismik empedanslar dikkat çekmektedir. Bu durum hem teorik hem de Nakamura yöntemiyle elde edilen Y/D spektrumları incelendiğinde de ortaya çıkmaktadır.

$\mathrm{Bu}$ çalışma sonuçları klasik sismik yöntemlerin lojistik/finansman gibi sebepler ile uygulanamadığı alanlarda S-dalga hızlarının ön kestirimi ile birçok sismik tehlike ve 
mühendislik sismolojisi gibi çalışmalar yürüten araştırmacılara ışık tutacağı düşünülmektedir.

\section{KATKI BELIRTME}

Yatay/Düşey Spektral oran ve eliptisite hesaplamalarında GEOPSY (Sesame 2004) algoritması kullanılmıştır. Şekil 1 GMT programı (Wessel vd., 2013) kullanılarak hazırlanmıştır. İstasyonlara ait jeolojik veriler MTA çizim editöründen alınmıştır (Akbaş vd., 2013). Çalışma alanındaki tektonik birimler (Şekil 1) MTA diri fay haritasından sayısallaştırılmıştır (Emre vd., 2013, 2018). Şekil 2a'daki sayısal verilerin gösteriminde SEISAN programından yararlanılmıştır (Havskov ve Ottemoller, 1999). Bu çalışmada F.Baliva'nın Herrmann ve Ammon (2002) çalışmalarından yararlanarak geliştirdiği SurWave yazılımı kullanılmıştır. Yazarlar, bu araştırmaya veri desteği sağlayan T.C. İçişleri Bakanlığı Afet ve Acil Durum Yönetimi Başkanlığı (AFAD) Deprem Daire Başkanlığına ve Atatürk Üniversitesi Deprem Araştırma Merkezine (ATA-DAM) teşekkür eder.

\section{KAYNAKLAR}

Akbaş, B., Akdeniz, N., Aksay, A., Altun, I., Balci, V., Bilginer E., et al., 2013. Turkey Geological Map, General Directorate of Mineral Research and Exploration, Ankara-Turkey. http://yerbilimleri.mta.gov.tr (Erişim Tarihi: 15.12.2019).

Akkaya, İ., Özvan, A., 2019. Site characterization in the Van settlement (Eastern Turkey) using surface waves and HVSR microtremor methods. Journal of Applied Geophysics, 160, 157-170.

Aki, K., 1965. A note on the use of microseisms in determining the shallow structures of the Earth's crust. Geophysics, 30(4), 665-666.

Akkaya, İ., Özvan, A., 2019. Site characterization in the Van settlement (Eastern Turkey) using surface waves and HVSR microtremor methods. Journal of Applied Geophysics, 160, 157-170. 
Anggono, T., Febriani, F., Amran, A., 2019. Inversion of shallow subsurface structure from Rayleigh ellipticity beneath a station in Tangerang, Indonesia. In Journal of Physics: Conference Series (Vol. 1153, No. 1, p. 012013). IOP Publishing.

Ashayeri, I., Biglari, M., Sadr, A., Haghshenas, E., 2019. Importance of revisiting (Vs) 30 site class index, Sarpol-e-zahab Mw= 7.3 earthquake., in Proceedings, 7th International Conference on Earthquake Geotechnical Engineering, 17-20 June, 2019, Rome, Italy.

Bekler, T., Demirci, A., Ekinci, Y. L., Büyüksaraç, A., 2019. Analysis of local site conditions through geophysical parameters at a city under earthquake threat: Çanakkale, NW Turkey. Journal of applied geophysics, 163, 31-39.

BSSC (Building Seismic Safety Council), 1997. NEHRP recommended provisions for Seismic Regulations for New Buildings and Other Structures. Part I, Provisions (FEMA 302), 334 pp

Burjánek, J., Poggi, V., Fäh, D., Gassner-Stamm, G., 2011. Estimation of local site effects in the Upper Valais (Switzerland). In Proceedings of 4th IASPEI/IAEE International Symposium: Effects of Surface Geology on Seismic Motion, Santa Barbara, United States. IASPEI and IAEE.

Büyüksaraç, A., Bektaş, Ö., Yılmaz, H., Arısoy, M. Ö., 2013. Preliminary seismic microzonation of Sivas city (Turkey) using microtremor and refraction microtremor (ReMi) measurements. Journal of seismology, 17(2), 425-435.

Büyüksaraç, A., Över, S., Geneş, M. C., Bikçe, M., Kacin, S., Bektaş, Ö., 2014. Estimating shear wave velocity using acceleration data in Antakya (Turkey). Earth Sciences Research Journal, 18(2), 87-98.

CEN, 2004. Eurocode 8-Design of Structure for Earthquake Resistance. Part I: General Rules, Seismic Actions and Rules for Buildings. European Standard EN 1998-1, December 2004, European Committee for Standardization, Brussels.

Darko, A. B., Molnar, S., Sadrekarimi, A., 2020. Blind comparison of non-invasive shear wave velocity profiling with invasive methods at bridge sites in Windsor, Ontario. Soil Dynamics and Earthquake Engineering, 129, 105906.

Demirtaş, R., Yağyemez, B., Penirci, O., Uğraş, M., 2010. Erzurum ili Büyük şehir Belediyesi Yerleşim Alanının 1/5000 ölçekli Nazım İmar Planına Esas Jeolojik- 
Jeoteknik Etüt Raporu. Erzurum İmar Planına Esas Jeolojik-Jeoteknik Etüt Raporu (yayımlanmamış).

Destici, C., 2001. Sismik dalga hızları ile dinamik ve statik parametrelerin ilişkilendirilmesi, SDÜ MMF Jeofizik Müh. Böl. Lisans Tezi, Isparta (yayınlanmamıştır).

Emre, O., Duman, T. Y., Ozalp, S., Elmaci, H., Olgun, S., Saroglu, F., 2013. 1/1.250.000 scaled Turkey active fault map, General Directorate of Mineral Research and Exploration special publication. Available: http://www.mta.gov.tr/ (July 2, 2019)

Emre, O., Duman, T. Y., Ozalp, S., Saroglu, F., Olgun, S., Elmaci, H., Çan, T., 2018. Active fault database of Turkey. Bulletin of Earthquake Engineering, 16, 32293275.

Fäh, D., Kind, F., Giardini, D., 2003. Inversion of local S-wave velocity structures from average $\mathrm{H} / \mathrm{V}$ ratios, and their use for the estimation of site-effects. Journal of Seismology, 7(4), 449-467.

Fäh, D., Kind, F., Giardini, D., 2001. A theoretical investigation of average H/V ratios. Geophys. J. Int., 145, 535-549. (doi: 10.1046/j.0956-540x.2001.01406.x)

Fäh, D., Wathelet, M., Kristekova, M., Havenith, H. B., Endrun, B., Stamm, G., Poggi, V, Burjanek J., Cornou, C., 2009. Using Ellipticity Information for Site Characterisation. Technical report, NERIES JRA4 Task B2-D4.

Havskov, J., Ottemoller, L., 1999. SeisAn Earthquake analysis software, Seismological Research Letters (1999) 70 (5): 532-534. Available: http://www.seismosoc.org/publications/SRL/SRL_70/srl_70-5_es.html (July 2, 2019).

Herrmann, R. B., Ammon, C. J., 2002. Computer programs in seismology: Surface waves, receiver functions and crustal structure. St. Louis University, St. Louis, $\mathrm{MO}$.

Issaadi, A., Semmane, F., Yelles-Chaouche, A., Galiana-Merino, J. J., Layadi, K., 2020. A Shear-Wave Velocity Model in the City of Oued-Fodda (Northern Algeria) from Rayleigh Wave Ellipticity Inversion. Applied Sciences, 10(5), 1717.

Keçeli, D. A., 2009. Uygulamalı Jeofizik. TMMOB JFMO Eğitim Yayınları, (9). 
Komazawa, M., Morikawa, H., Nakamura, K., Akamatsu, J., Nishimura, K., Sawada, S., Erken, A., Onalp, A., 2002. Bedrock structure in Adapazari, Turkey-a possible cause of severe damage by the 1999 Kocaeli earthquake. Soil Dynamics and Earthquake Engineering 22 (9), 829-836.

Konno, K., T. Ohmachi 1998. Ground-motion characteristics estimated from spectral ratio between horizontal and vertical components of microtremor. Bull. Seism. Soc. Am., 88, 228-241.

Layadi, K., Semmane, F., Yelles-Chaouche, A., 2018. S-wave velocity structure of Chlef City, Algeria, by inversion of Rayleigh wave ellipticity. Near Surface Geophysics, 16(3), 328-339.

Marcucci, S., Milana, G., Hailemikael, S., Carlucci, G., Cara, F., Di Giulio, G., Vassallo, M., 2019. The deep bedrock in Rome, Italy: a new constraint based on passive seismic data analysis. Pure and Applied Geophysics, 176(6), 23952410.

Mirzaoğlu, M., Dikmen, Ü., 2003. Application of microtremors to seismic microzoning procedure. Journal of the Balkan Geophysical Society, 6(3), 143-156.

Nakamura, Y., 1989. A method for dynamic characteristics estimation of subsurface using microtremor on the ground surface. Railway Technical Research Institute, Quarterly Reports, 30(1).

Nogoshi, M., Igarashi, T., 1971. On the amplitude characteristics of ambient noise (Part 2). J Seismol Soc Jpn, 24, 26-40.

Ozer, C., Ozyazicioglu, M., 2019. The Local Earthquake Tomography of Erzurum (Turkey) Geothermal Area. Earth Sciences Research Journal, 23(3), 209-223.

Över, S., Büyüksaraç, A., Bektas, Ö., Filazi, A., 2011. Assessment of potential seismic hazard and site effect in Antakya (Hatay Province), SE Turkey. Environmental Earth Sciences, 62(2), 313-326.

Özer, C., Kocadagistan, M.E., Perk, S., 2019. Earthquake monitoring network of Erzurum: ATANET. International Journal of Scientific and Technological Research. Vol.5, No.8, 35-47.

Özer, Ç., 2019. Erzurum ve çevresinin yerel zemin etkilerinin incelenmesi. Dokuz Eylül Üniversitesi Mühendislik Fakültesi Fen ve Mühendislik Dergisi, 21(61), 247-257. 
Pamuk, E., Doğru, F., Dindar, H., 2015. Yüzey dalgası dispersiyon verisinin ardışık ters çözümü. Yerbilimleri Dergisi, 36(1), 1-18.

Pamuk, E., Özdağ, Ö. C., Akgün, M., 2019. Soil characterization of Bornova Plain (Izmir, Turkey) and its surroundings using a combined survey of MASW and ReMi methods and Nakamura's (HVSR) technique. Bulletin of Engineering Geology and the Environment, 78(4), 3023-3035.

Pamuk, E., Özdağ, Ö. C., Tunçel, A., Özyalın, Ş., Akgün, M., 2018. Local site effects evaluation for Aliağa/İzmir using HVSR (Nakamura technique) and MASW methods. Natural Hazards, 90(2), 887-899.

Parolai, S., Richwalski, S. M., Milkereit, C., Fäh, D., 2006. S-wave velocity profiles for earthquake engineering purposes for the Cologne area (Germany). Bulletin of Earthquake Engineering, 4(1), 65-94.

Picotti, S., Francese, R., Giorgi, M., Pettenati, F., Carcione, J. M., 2017. Estimation of glacier thicknesses and basal properties using the horizontal-to-vertical component spectral ratio (HVSR) technique from passive seismic data. Journal of Glaciology, 63(238), 229-248.

Rezaei, S., Shooshpasha, I., Rezaei, H., 2020. Evaluation of ground dynamic characteristics using ambient noise measurements in a landslide area. Bulletin of Engineering Geology and the Environment, 79:1749-1763.

Rosa-Cintas, S., Clavero, D., Delgado, J., López-Casado, C., Galiana-Merino, J. J., Garrido, J., 2017. Characterization of the shear wave velocity in the metropolitan area of Málaga (S Spain) using the H/V technique. Soil Dynamics and Earthquake Engineering, 92, 433-442.

Sambridge, M., 1999. Geophysical inversion with a neighbourhood algorithm I. Searching a parameter space. Geophysical Journal International.138:479-94.

SESAME, 2004. Site effects assessment using ambient excitations: Final Report, uropean Commission \# Research General Directorate, Project EVG1-CT-200000026 SESAME. Available online at http://sesame-fp5.obs.ujf-grenoble.fr/

Shabani, E., Cornou, C., Haghshenas, E., Wathelet, M., Bard, P. Y., Mirzaei, N., \& Eskandari-Ghadi, M., 2008. Estimating shear-waves velocity structure by using array methods (FK and SPAC) and inversion of ellipticity curves at a site in south of Tehran. In Proceedings of the 14th Word Conference on Earthquake Engineering (pp. 12-17). 
TDY (Türk Deprem Yönetmeliği), 2018. Deprem Bölgelerinde Yapılacak Binalar Hakkında Esaslar. AFAD Deprem Dairesi Başkanlığı.

Türkkan, L., 2015. Sürekli dalgacık dönüşümü ile yüzey ölçümü (Yüksek Lisans Tezi, Namık Kemal Üniversitesi).

Ullah, I., Prado, RL., 2017. Soft sediment thickness and shear-wave velocity estimation from the $\mathrm{H} / \mathrm{V}$ technique up to the bedrock at meteorite impact crater site, Sao Paulo city, Brazil. Soil Dynamics and Earthquake Engineering, 94, 215-222.

Ullah, I., 2017. Near-surface characterization from the H/V spectral curves along with the joint inversion of the ellipticity and dispersion curves. Doktora Tezi, São Paulo Üniversitesi, Brezilya.

Uyanık, O., 2002. Kayma Dalga Hızına Bağlı Potansiyel Sıvılaşma Analiz Yöntemi, Doktora Tezi, DEU Fen Bilimleri Enstitüsü, İzmir, 200s.

Uyanık, O., Çatıoğlu, B., 2015. Sismik Hızlardan Yoğunluğun Belirlenmesi. Jeofizik dergisi. 17, 3-15

Wathelet, M., 2005. Array recordings of ambient vibrations: surface-wave inversion. Doktora tezi, Liege Üniversitesi, Belçika.

Wessel, P., Smith, W. H., Scharroo, R., Luis, J., Wobbe, F., 2013. Generic mapping tools: improved version released. Eos, Transactions American Geophysical Union. 94(45), 409-410.

Yalçınkaya, E., Alptekin, O., 2005. Site effect and its relationship to the intensity and damage observed in the June 27, 1998 Adana-Ceyhan earthquake. Pure and Applied Geophysics, 162(5), 913-930.

Yamanaka, H., Takemura, M., Ishida, H., Niea, M., 1994. Characteristics of longperiod microtremors and their applicability in exploration of deep layers. Bull. Seism. Soc. Am. 84, 1831-1841. 